\title{
ESR, Zero-Field Splitting, and Magnetic Exchange of Exchange-Coupled Copper(II)-Copper(II) Pairs in Copper(II) Tetraphenylporphyrin N-Oxide\#
}

\author{
Fuh-An Yang, ${ }^{\dagger}$ Chih-Wei Guo, ${ }^{\dagger}$ Yao-Jung Chen, ${ }^{\dagger}$ Jyh-Horung Chen, ${ }^{*, \dagger}$ Shin-Shin Wang, ${ }^{\ddagger}$ Jo-Yu Tung,,$\$$ \\ Lian-Pin Hwang," and Shanmugam Elango ${ }^{\perp}$ \\ Department of Chemistry, National Chung-Hsing University, Taichung 40227, Taiwan, Material \\ and Chemical Research Laboratories, Hsin-Chu 300, Taiwan, Chung Hwa College of Medical \\ Technology, Tainan 717, Taiwan, and Department of Chemistry, National Taiwan University and \\ Institute of Atomic and Molecular Sciences, Academia Sinica, Taipei 10764, Taiwan
}

Received June 28, 2006

\begin{abstract}
The crystal structures of the dimer form of copper(II) tetraphenylporphyrin $\mathrm{N}$-oxide, $[\mathrm{Cu}(\mathrm{tpp}-\mathrm{N}-\mathrm{O})]_{2}$ (3-dimer), and zinc(II) tetraphenylporphyrin $\mathrm{N}$-oxide, $[\mathrm{Zn}(\mathrm{tpp}-\mathrm{N}-\mathrm{O})]_{2}$ (4-dimer), were established. The geometry at the copper ion in 3-dimer is essentially square-pyramidal with one oxygen bridge $[\mathrm{O}(1 \mathrm{~A})]$ occupying the apical site, giving a much larger $\mathrm{Cu}-\mathrm{O}$ bond distance compared to those at the basal plane. The respective $\mathrm{Cu} \cdots \mathrm{Cu}$ distance and $\mathrm{Cu}-\mathrm{O}-$ Cu angle in the core of 3-dimer are 3.987(4) $\AA$ and $148.1(3)^{\circ}$. The $\mathrm{Zn}(1)$ atom in 4-dimer has a distorted squarepyramidal $[4+1]$ coordination geometry that gives a $\tau$-value of 0.19 . The respective $\mathrm{Zn} \cdots \mathrm{Zn}$ distance and $\mathrm{Zn}$ $\mathrm{O}-\mathrm{Zn}$ angle in the dimeric unit of 4-dimer are 4.025(3) $\AA$ and $148.1(2)^{\circ}$. The 3-dimer displays axial X-band electron paramagnetic resonance spectral features $\left(E_{\mathrm{s}}=0\right)$ in the powder state at $4 \mathrm{~K}$, giving $g_{\|}=2.51\left(A_{\|, \mathrm{s}}=(9.6 \pm 0.2)\right.$ $\times 10^{-3} \mathrm{~cm}^{-1}$ ) and $g_{\perp}=2.11$ and in the same powder state at $293 \mathrm{~K}$ giving $D_{\mathrm{s}}=0.0731 \mathrm{~cm}^{-1}$ (as derived from $\Delta M_{\mathrm{s}}=1$ lines) or $0.0743 \mathrm{~cm}^{-1}$ (as derived from the $\Delta M_{\mathrm{s}}=2$ lines). In addition, 3-dimer displays a $\Delta M_{\mathrm{s}}=2$ transition at $g=4.17$ indicating the presence of spin-exchange coupling. The anisotropic exchange interaction ( $D_{\mathrm{s}}^{\mathrm{ex}}=0.132 \mathrm{~cm}^{-1}$ ) gives the main contribution to $D_{\mathrm{s}}$ in 3-dimer. The theoretical fit of the susceptibility and effective magnetic moment data of 3-dimer in the temperature range of $5-300 \mathrm{~K}$ gives $2 \mathrm{~J}=68 \mathrm{~cm}^{-1}, g=2.01, p=0.06$, and a temperature-independent paramagnetism of $10^{-6} \mathrm{~cm}^{3} \mathrm{~mol}^{-1}$. This magnetic susceptibility data indicates that the copper(II) ions in 3-dimer are coupled in a ferromagnetic manner with the ground-spin triplet stabilized by 68 $\mathrm{cm}^{-1}$ with regard to the singlet.
\end{abstract}

\section{Introduction}

Metalloporphyrins with a bridged structure between the central metal and one of the four pyrrole nitrogens have drawn much attention in recent times, and so far, bridged metalloporphyrins with a metal $-\mathrm{O}-\mathrm{N}$ linkage (metal $=$ $\left.\mathrm{Ni},{ }^{1,2} \mathrm{Tl}^{3}\right)$, metal $-\mathrm{N}-\mathrm{N}$ linkage $\left(\right.$ metal $=\mathrm{Zn},{ }^{4,5,6} \mathrm{Ni},{ }^{7,8} \mathrm{Fe},{ }^{5,9}$

* To whom correspondence should be addressed. E-mail: jyhhchen@ dragon.nchu.edu.tw.

† National Chung-Hsing University.

$\doteqdot$ Material and Chemical Research Laboratories.

$\S$ Chung Hwa College of Medical Technology.

"National Taiwan University and Institute of Atomic and Molecular Sciences.

$\perp$ Present address: Institute of Chemical and Engineering Sciences, Singapore 627833, Singapore.

\# Dedicated to Professor Rob Dunbar (Case Western Reserve University) on the occasion of his 65 th birthday.

(1) Balch, A. L.; Chan, Y. W.; Olmstead, M. M. J. Am. Chem. Soc. 1985, 107,6510 .

578 Inorganic Chemistry, Vol. 46, No. 2, 2007
$\left.\mathrm{Tl}^{7,10,11} \mathrm{Ga}^{10,11}\right)$, and metal- $\mathrm{C}-\mathrm{N}$ linkage $\left(\right.$ metal $\left.=\mathrm{Fe}^{12}\right)$ have been reported. Balch and co-workers ${ }^{1,2}$ reported that

(2) Balch, A. L.; Chan, Y. W.; Olmstead, M. M.; Renner, M. W. J. Am. Chem. Soc. 1985, 107, 2393.

(3) Yang, F. A.; Cho, K. Y.; Chen, J. H.; Wang, S. S.; Tung, J. Y.; Hsieh, H. Y.; Liao, F. L.; Lee, G. H.; Hwang, L. P.; Elango, S. Polyhedron, in press.

(4) Li, Y. I.; Chang, C. S.; Tung, J. Y.; Tsai, C. H.; Chen, J. H.; Liao, F. L.; Wang, S. L. Polyhedron 2000, 19, 413.

(5) Chen, C. H.; Lee, Y. Y.; Liau, B. C.; Elango, S.; Chen, J. H.; Hsien, H. Y.; Liao, F. L.; Wang, S. L.; Hwang, L. P. J. Chem. Soc., Dalton Trans. 2002, 3001.

(6) Yang, F. A.; Chen, J. H.; Hsieh, H. Y.; Elango, S.; Hwang, L. P. Inorg. Chem. 2003, 42, 4603.

(7) Chang, C. S.; Chen, C. H.; Li, Y. I.; Liau, B. C.; Ko, B. T.; Elango, S.; Chen, J. H.; Hwang, L. P. Inorg. Chem. 2001, 40, 2905.

(8) Callot, H. J.; Chevrier, B.; Weiss, R. J. Am. Chem. Soc. 1978, 100, 4733.

(9) Mahy, J. P.; Battioni, P.; Mansuy, D. J. Am. Chem. Soc. 1986, 108, 1079.

(10) Tung, J. Y.; Jang, J. I.; Lin, C. C.; Chen, J. H.; Hwang, L. P. Inorg. Chem. 2000, 39, 1106.

10.1021/ic0611802 CCC: $\$ 37.00$ @ 2007 American Chemical Society Published on Web 12/21/2006 
the insertion of nickel(II) into $\mathrm{H}_{2}(\mathrm{OEP}-\mathrm{N}-\mathrm{O})(\mathrm{OEP}=$ dianion of octaethylporphyrin) produced the complex $\mathrm{Ni}(\mathrm{OEP}-\mathrm{N}-\mathrm{O})$ (1), in which the metal ions are bound to a nearly planar set of three nitrogen atoms and one oxygen atom. Due to the difficulties in obtaining a crystal suitable for absolute structural assignment by X-ray method, Balch and coworkers ${ }^{2}$ characterized the complex copper(II) octaethylporphyrin $N$-oxide, $\mathrm{Cu}(\mathrm{OEP}-\mathrm{N}$-O) (2), by infrared, UV-vis, and electron spin resonance (ESR) spectroscopy. Judging by both an isotropic ESR spectrum obtained from a toluene solution at $23{ }^{\circ} \mathrm{C}$ and an anisotropic spectrum obtained from a $1 \%$ sample (2) doped in octaethylporphyrin $\mathrm{N}$-oxide at $23{ }^{\circ} \mathrm{C}$, they claimed that $\mathbf{2}$ has a structure analogous to $\mathbf{1}$ and is a monomeric species. Owing to the failure in measuring the ESR spectrum for $\mathbf{2}$ in solid phase, they lost the structural information for the same compound in the powder and crystalline phase. Upon replacement of $\mathrm{OEP}^{2-}$ with tpp ${ }^{2-}$ $($ tpp $=$ dianion of meso-tetraphenylporphyrin), complex 2 became a new, monomeric compound $\mathrm{Cu}(\mathrm{tpp}-\mathrm{N}-\mathrm{O})(\mathbf{3})$. We have recently reported ${ }^{3}$ the X-ray structure of diamagnetic, mononuclear, six-coordinate and bridged thallium complex of $\mathrm{Tl}(\mathrm{tpp}-\mathrm{N}-\mathrm{O})(\mathrm{OAc})$. It is interesting to figure out the magnetic property for the paramagnetic species $\mathbf{3}$ in both solid and solution phases. Structural characteristics of binuclear copper complexes, such as dimeric copper(II) species, have been reported in the past. ${ }^{13}$ ESR studies of copper(II) dimers, namely, di( $\mu$-oxo)-bridged copper(II) complexes, had been extensively investigated by Gatteschi et al. and Pibrow and co-workers ${ }^{14-16}$ to elucidate the exchange interactions between the ground and excited states in these structures. Barker et al. ${ }^{17}$ reported the magnetic exchange between neighboring copper centers in copper(II) tetraphenylporphyrin $[\mathrm{Cu}(\mathrm{tpp})]$, using ESR spectroscopy to detect the low field $\Delta M_{\mathrm{s}}=2$ transition. Indeed, it is not easy to prepare the dimeric forms of copper(II)- porphyrin, $[\mathrm{Cu}(\text { por })]_{2}$ (por $=$ porphyrin), and consequently, direct investigation of the intermolecular copper-copper interaction, $J(\mathrm{Cu}-\mathrm{Cu})$ (or $\left.J_{\mathrm{dd}}\right)$, is difficult in $[\mathrm{Cu}(\text { por })]_{2}$. Moreover, the formation of dimeric species is common in metalloporphyrin $\pi$-cation radical systems. ${ }^{18,19}$ A thorough study of magnetic interaction between paramagnetic metal centers and the porphyrin $\pi$-cation radical is relatively limited with copper systems such as $\mathrm{Cu}(\text { por })^{\circ+}$, the most studied..$^{18}$ The ground state of the dimer of $\left[\mathrm{Cu}(\text { por })^{\bullet+}\right]_{2}$ is determined by three types of isotropic exchange interactions, namely, $J(\mathrm{Cu}-$ $\mathrm{Cu})\left(\right.$ or $\left.J_{\mathrm{dd}}\right), J\left(\right.$ radical-radical) $\left(\right.$ or $\left.J_{\pi-\pi}\right)$, and $J(\mathrm{Cu}-$ radical $)$

(11) Shil, W. Z.; Cho, K. Y.; Cheng, C. W.; Chen, J. H.; Wang, S. S.; Liao, F. L.; Tung, J. Y.; Elango, S. Polyhedron 2006, 25, 1864.

(12) Olmstead, M. M.; Cheng, R. J.; Balch, A. L. Inorg. Chem. 1982, 21, 4143.

(13) Hatfield, W. E. Inorg. Chem. 1972, 11, 216.

(14) Banci, L.; Bencini, A.; Gatteschi, D. J. Am. Chem. Soc. 1983, 105, 761.

(15) Boillot, M. L.; Journaux, Y.; Bencini, A.; Gatteschi, D. Inorg. Chem. 1985, 24, 263

(16) Boyd, P. D. W.; Toy, A. D.; Smith, T. D.; Pibrow, J. R. J. Chem. Soc., Dalton Trans. 1973, 1549.

(17) Barker, P. J.; Stobart, S. R. Chem. Commun. 1980, 969.

(18) Mengersen, C.; Subramanian, J.; Fuhrhop, J. H. Mol. Phys. 1976, 32 , 893.

(19) Neal, T. J.; Kang, S. J.; Schulz, C. E.; Scheidt, W. R. Inorg. Chem. 1999, 38, 4294. (or $\left.J_{\mathrm{d} \pi}\right) .{ }^{17} \mathrm{In} \mathrm{Cu}(\mathrm{tpp}-\mathrm{N}-\mathrm{O}$ ), the molecules could be associated into dimers by secondary bonds between an electronegative oxygen of one monomer and a copper of the other in the solid phase, giving an approximate square pyramidal geometry around copper. The $\mathrm{Cu}(\mathrm{tpp}-\mathrm{N}-\mathrm{O})$ might exist as the dimer form $[\mathrm{Cu}(\mathrm{tpp}-\mathrm{N}-\mathrm{O})]_{2}$ (3-dimer) in solid state. X-ray diffraction data confirms that the presumed monomer of $\mathrm{Cu}$ (tpp- $\mathrm{N}$-O) turned out to be a dimer (3-dimer) in solid phase. This 3-dimer is a dimeric form of $[\mathrm{Cu}(\text { por })]_{2}$. The intermolecular $J_{\pi-\pi}$ and intramolecular $J_{\mathrm{d} \pi}$ interactions are neglected; only the intermolecular $J_{\mathrm{dd}}$ interaction needs to be considered in magnetic coupling for 3-dimer. Consequently, the quantity $J_{\mathrm{dd}}$ for 3-dimer has been experimentally measured in the present work. Upon replacement of $\mathrm{Cu}$ (II) in 3-dimer with zinc(II), a new, diamagnetic compound forms, [Zn(tpp- $N$ $\mathrm{O})]_{2}$ (4-dimer), still with a dimeric structure. The latter complex of 4-dimer is an analogous diamagnetic metal complex and is used as a diamagnetic correction for $\mathbf{3}$-dimer in the solid-state magnetic susceptibility measurements.

To examine possible pathways for magnetic coupling, we have determined the crystal structures of 3-dimer and 4-dimer. Furthermore, two complementary techniques are employed to study the electronic nature of $\mathbf{3}$-dimer. Studies of temperature dependence of the magnetic susceptibility and of the effective magnetic moment show that the pair of copper(II) atoms are ferromagnetically coupled, giving an $S$ $=1$ ground state and $S=0$ level $|2 J|$ above this. ${ }^{20,21}$ Application of the Bleaney and Bowers ${ }^{22}$ equation permits evaluation of $|2 J|$ and an average $g$ value for powder samples. Measurement of the ESR spectra arising from 3-dimer with the $S=1$ state and application of the spin Hamiltonian (eq 3 ) permits derivation of the zero-field splitting parameters $D_{\mathrm{s}}$ and $E_{\mathrm{s}}$. Eaton and co-workers reported that the distance between the copper atoms in the copper porphyrins dimers was determined from the ratio of the intensity of the halffield transitions to the intensity of the allowed transitions. ${ }^{23}$ This report is the first unambiguous analysis of zero-field splitting and magnetic exchange interaction in a copperporphyrin complex. In addition, some of the results of solution and solid-state ESR measurements for 3-dimer are described.

\section{Experimental Section}

[Cu(tpp- $\mathrm{N}-\mathrm{O})]_{2}$ (3-Dimer). A mixture of $\mathrm{H}_{2}(\mathrm{tpp}-\mathrm{N}-\mathrm{O})(0.063$ $\mathrm{g}, 0.1 \mathrm{mmol})$ in $\mathrm{CH}_{2} \mathrm{Cl}_{2}(10 \mathrm{~mL})$ and $\mathrm{Cu}(\mathrm{OAc})_{2}(0.04 \mathrm{~g}, 0.22 \mathrm{mmol})$ in $\mathrm{MeOH}(5 \mathrm{~mL})$ was refluxed for $1 \mathrm{~h} .{ }^{24,25}$ After it was concentrated, the residue was redissolved in $\mathrm{CH}_{2} \mathrm{Cl}_{2}$ and the solution was dried with anhydrous $\mathrm{Na}_{2} \mathrm{SO}_{4}$ and filtered. The filtrate was concentrated again and recrystallized from $\mathrm{CH}_{2} \mathrm{Cl}_{2}-\mathrm{MeOH}[1: 3$ (v/v)], affording the purple solids of 3-dimer (0.05 g, $0.0361 \mathrm{mmol}, 36.1 \%)$, which

(20) Duggan, D.; Hendrickson, D. N. Inorg. Chem. 1974, 13, 2929.

(21) Drago, R. S. Physical Methods for Chemists, 2nd ed.; Saunders College Publishing: New York, 1992; pp 473-475, 591-593.

(22) Bleaney, B.; Bowers, K. D. Proc. R. Soc. London 1952, A214, 451.

(23) Eaton, S. S.; Eaton, G. R.; Chang, C. K. J. Am. Chem. Soc. 1985, 107, 3177.

(24) Tsurumark, H.; Watanabe, Y.; Morishima, I. Inorg. Chem. 1994, 33, 4186.

(25) Andrews, L. E.; Bonnett, R.; Ridge, R. J.; Appelman, E. H. J. Chem. Soc., Perkin Trans. 1 1983, 103. 
Yang et al.

was again dissolved in $\mathrm{CHCl}_{3}$ and layered with $\mathrm{MeOH}$ to get purple crystals for single-crystal X-ray analysis. FAB-MS, $m / z$ (assignment, rel intensity): $154\left([\mathrm{NBA}+\mathrm{H}]^{+}, 100\right) ; 614\left(\left[\mathrm{H}_{2} \mathrm{tpp}\right]^{+}, 9.48\right) ; 630$ $\left(\left[\mathrm{H}_{2} \mathrm{tpp}-\mathrm{N}-\mathrm{O}\right]^{+}, 3.38\right) ; 691\left([\mathrm{Cu}(\mathrm{tpp}-\mathrm{N}-\mathrm{O})]^{+}, 48.38\right) ; 692([\mathrm{Cu}(\mathrm{tpp}-$ $N-\mathrm{O})+\mathrm{H}]^{+}$, 39.66). UV-vis spectrum, $\lambda(\mathrm{nm})\left[\epsilon \times 10^{-3}, \mathrm{M}^{-1}\right.$ $\mathrm{cm}^{-1}$ ] in $\mathrm{CH}_{2} \mathrm{Cl}_{2}$ : 429 (52.3), 564.0 (4.2), 604 (4.2).

[Zn(tpp- $\mathbf{N - O})]_{2}$ (4-Dimer). A mixture of $\mathrm{H}_{2}(\operatorname{tpp}-\mathrm{N}-\mathrm{O})(0.063$ $\mathrm{g}, 0.1 \mathrm{mmol})$ and $\mathrm{Zn}(\mathrm{OAc})_{2}(0.04 \mathrm{~g}, 0.2 \mathrm{mmol})$ in pyridine $(10$ $\mathrm{mL}$ ) was refluxed for $30 \mathrm{~min} .{ }^{24,25}$ After the solution was concentrated, the residue was dissolved in $\mathrm{CH}_{2} \mathrm{Cl}_{2}$, dried with anhydrous $\mathrm{Na}_{2} \mathrm{SO}_{4}$, and the solution was filtered. The filtrate was chromatographed on silica gel (60 g, 70-230 mesh). The major green band eluting with $\mathrm{CH}_{2} \mathrm{Cl}_{2}$-pyridine (10:1 (v/v)) was collected and concentrated. Removal of the solvent and recrystallization from pyridine-hexane $(1: 3(\mathrm{v} / \mathrm{v}))$ gave purple crystals of 4-dimer $(0.4$ g, $0.029 \mathrm{mmol}, 29 \%$ ). Compound 4-dimer was redissolved in a trace amount of pyridine to give purple crystals for single-crystal $\mathrm{X}$-ray analysis.

${ }^{1} \mathrm{H}$ NMR $\left(400 \mathrm{mHz}, \mathrm{CDCl}_{3}, 20{ }^{\circ} \mathrm{C}\right): \delta 9.02\left(\mathrm{~s}, \mathrm{H}_{\beta}\right) ; 8.98\left(\mathrm{~d}, \mathrm{H}_{\beta}\right.$, $\left.{ }^{3} J(\mathrm{H}-\mathrm{H})=4.4 \mathrm{~Hz}\right) ; 8.82\left(\mathrm{~d}, \mathrm{H}_{\beta},{ }^{3} J(\mathrm{H}-\mathrm{H})=4.4 \mathrm{~Hz}\right) ; 6.90(\mathrm{~s}$, $\mathrm{H}_{\beta}$ ); 8.45 (s, o-H; o-H represents ortho-phenyl protons); 8.31 (s, $o-\mathrm{H}) ; 7.80-7.85$ (m, meta and para phenyl protons). FAB-MS, $m / z$ (assignment, rel intensity): $154\left([\mathrm{NBA}+\mathrm{H}]^{+}, 100\right) ; 614\left(\left[\mathrm{H}_{2}-\right.\right.$ tpp $\left.]^{+}, 15.40\right) ; 630\left(\left[\mathrm{H}_{2} \mathrm{tpp}-\mathrm{N}-\mathrm{O}\right]^{+}, 9.94\right) ; 631\left(\left[\mathrm{H}_{2} \mathrm{tpp}-\mathrm{N}-\mathrm{O}+\mathrm{H}\right]^{+}\right.$, 12.50); $692\left([\mathrm{Zn}(\operatorname{tpp}-\mathrm{N}-\mathrm{O})]^{+}, 53.20\right) ; 693\left([\mathrm{Zn}(\operatorname{tpp}-\mathrm{N}-\mathrm{O})+\mathrm{H}]^{+}\right.$, 44.83). $\mathrm{UV}-$ vis spectrum, $\lambda(\mathrm{nm})\left[\epsilon \times 10^{-3}, \mathrm{M}^{-1} \mathrm{~cm}^{-1}\right]$ in $\mathrm{CH}_{2}$ $\mathrm{Cl}_{2}: 420$ (63.4), 571 (2.5), 612 (2.5).

Magnetic Susceptibility Measurements. The solid-state magnetic susceptibility were measured under helium on a Quantum Design MPMS5 SQUID susceptometer from 5 to $300 \mathrm{~K}$ at a field of $5 \mathrm{kG}$. The sample was held in a Kel-F bucket. The bucket had been calibrated independently at the same field and temperature. The raw data for 3-dimer were corrected for the molecular diamagnetism. The diamagnetic contribution of the sample was measured from an analogous diamagnetic metal complex, i.e., 4-dimer. The details of the diamagnetic corrections made can be found in ref 21.

Spectroscopy. ESR spectra were measured on an X-band Bruker EMX-10 spectrometer equipped with an Oxford Instruments liquid helium cryostat. Magnetic field values were measured with a digital counter. The X-band resonator was a dual-mode cavity (Bruker ER 4116 DM). Proton NMR spectra were recorded at $599.95 \mathrm{MHz}$ on a Varian Unity Inova-600 spectrometer locked on deuterated solvent and referenced to the solvent peak. Proton NMR is relative to $\mathrm{CDCl}_{3}$ at $\delta=7.24$.

The positive-ion fast atom bombardment mass spectrum (FABMS) was obtained in a nitrobenzyl alcohol (NBA) matrix using a JEOL JMS-SX/SX 102A mass spectrometer. UV-vis spectra were recorded at $20{ }^{\circ} \mathrm{C}$ on a Hitachi U-3210 spectrophotometer.

Crystallography. Table 1 presents the crystal data as well as other information for 3-dimer $\cdot 2 \mathrm{CHCl}_{3}$ and 4-dimer-pyridine. Measurements were taken on a Bruker AXS SMART-1000 diffractometer using monochromatized Mo K $\alpha$ radiation $(\lambda=0.71073 \AA)$. Empirical absorption corrections were made for both complexes. The structures were solved by direct methods (SHELXTL-97) ${ }^{26}$ and refined by the full-matrix least-squares method. All nonhydrogen atoms were refined with anisotropic thermal parameters, whereas all hydrogen atoms except those protons of pyridine for 4-dimer-pyridine were placed in calculated positions and refined

(26) Sheldrick, G. M. SHELXL-97, Program for Refinement of Crystal Structure from Diffraction Data; University of Gottingen: Gottingen, Germany, 1997.
Table 1. Crystal Data for 3-Dimer-2 $\mathrm{CHCl}_{3}$ and 4-Dimer-Pyridine

\begin{tabular}{lll}
\hline \multicolumn{1}{c}{ formula } & $\mathrm{C}_{90} \mathrm{H}_{58} \mathrm{Cl}_{6} \mathrm{Cu}_{2} \mathrm{~N}_{8} \mathrm{O}_{2}$ & \multicolumn{1}{c}{$\mathrm{C}_{93} \mathrm{H}_{56} \mathrm{~N}_{9} \mathrm{O}_{2} \mathrm{Zn}_{2}$} \\
\hline fw & 1623.18 & 1462.22 \\
space group & $P \overline{1}$ & $P^{-}$ \\
cryst syst & triclinic & triclinic \\
$a, \AA$ & $11.2579(10)$ & $11.2537(8)$ \\
$b, \AA$ & $13.2668(11)$ & $13.1197(9)$ \\
$c, \AA$ & $13.8772(12)$ & $13.8526(10)$ \\
$\alpha$, deg & $74.468(2)$ & $73.0700(10)$ \\
$\beta$, deg & $77.592(2)$ & $77.825(2)$ \\
$\gamma$, deg & $67.561(2)$ & $66.5890(10)$ \\
$V, \AA^{3}$ & $1830.9(3)$ & $1785.0(2)$ \\
$Z$ & 1 & 1 \\
$F_{000}$ & 830 & 758 \\
$D_{\text {calcd, }}, \mathrm{cm}{ }^{-3}$ & 1.472 & 1.365 \\
$(\mathrm{Mo} \mathrm{K} \alpha), \mathrm{mm}^{-1}$ & 0.859 & 0.732 \\
$S$ & 0.954 & 1.036 \\
cryst size, mm & $0.20 \times 0.10 \times 0.10$ & $0.30 \times 0.20 \times 0.10$ \\
$\theta$, deg & 28.37 & 28.35 \\
$T, \mathrm{~K}$ & $295(2)$ & $294(2)$ \\
no. of reflns measd & 9080 & 8830 \\
no. of reflns obsd & 4180 & 5159 \\
$\mathrm{R} 1^{a}(\%)$ & 7.46 & 7.09 \\
wR2 ${ }^{b}(\%)$ & 21.10 & 20.29 \\
${ }^{a} \mathrm{R} 1=\left[\sum \| F_{\mathrm{o}}|-| F_{\mathrm{c}}|| / \sum\left|F_{\mathrm{o}}\right|\right] .{ }^{b} \mathrm{wR} 2=\left\{\sum\left[\mathrm{w}\left(F_{\mathrm{o}}{ }^{2}-F_{\mathrm{c}}{ }^{2}\right)^{2}\right] / \Sigma\left[\mathrm{w}\left(F_{\mathrm{o}}{ }^{2}\right)^{2}\right]\right\}^{1 / 2}$.
\end{tabular}

Table 2. Selected Bond Distances ( $\AA$ ) and Angles (deg) for Compounds 3-Dimer $\cdot 2 \mathrm{CHCl}_{3}$ and 4-Dimer-Pyridine

\begin{tabular}{|c|c|c|c|}
\hline \multicolumn{4}{|c|}{ 3-Dimer2 $\cdot \mathrm{CHCl}_{3}$} \\
\hline $\mathrm{Cu}(1)-\mathrm{N}(1)$ & $1.991(3)$ & $\mathrm{Cu}(1)-\mathrm{O}(1 \mathrm{~A})$ & $2.488(7)$ \\
\hline $\mathrm{Cu}(1)-\mathrm{N}(3)$ & $1.995(4)$ & $\mathrm{Cu}(1) \cdots \mathrm{Cu}(1 \mathrm{~A})$ & $3.987(4)$ \\
\hline $\mathrm{Cu}(1)-\mathrm{N}(4)$ & $2.332(4)$ & $\mathrm{Cu}(1)-\mathrm{O}(1)$ & $1.653(7)$ \\
\hline $\mathrm{Cu}(1)-\mathrm{N}(2)$ & $2.130(4)$ & $\begin{array}{l}\mathrm{Cu}(1)-\mathrm{O}\left(1^{\prime}\right) \\
\mathrm{Cu}(1) \cdots \mathrm{O}\left(1^{\prime} \mathrm{A}\right)\end{array}$ & $\begin{array}{l}1.775(4) \\
4.505(4)\end{array}$ \\
\hline $\begin{array}{l}\mathrm{O}(1 \mathrm{~A})-\mathrm{Cu}(1)-\mathrm{N}(1) \\
\mathrm{O}(1 \mathrm{~A})-\mathrm{Cu}(1)-\mathrm{N}(4) \\
\mathrm{O}(1 \mathrm{~A})-\mathrm{Cu}(1)-\mathrm{N}(3) \\
\mathrm{O}(1 \mathrm{~A})-\mathrm{Cu}(1)-\mathrm{O}(1) \\
\mathrm{N}(1)-\mathrm{Cu}(1)-\mathrm{N}(3) \\
\mathrm{N}(1)-\mathrm{Cu}(1)-\mathrm{N}(4)\end{array}$ & $\begin{array}{l}102.0(3) \\
118.3(3) \\
94.3(3) \\
31.9(3) \\
163.39(14) \\
88.07(13)\end{array}$ & $\begin{array}{l}\mathrm{Cu}(1)-\mathrm{O}(1)-\mathrm{Cu}(1 \mathrm{~A}) \\
\mathrm{O}(1)-\mathrm{Cu}(1)-\mathrm{N}(1) \\
\mathrm{O}(1)-\mathrm{Cu}(1)-\mathrm{N}(4) \\
\mathrm{O}(1)-\mathrm{Cu}(1)-\mathrm{N}(3) \\
\mathrm{N}(4)-\mathrm{Cu}(1)-\mathrm{N}(3)\end{array}$ & $\begin{array}{l}148.1(3) \\
98.1(3) \\
150.2(3) \\
93.9(3) \\
87.12(14)\end{array}$ \\
\hline \multicolumn{4}{|c|}{ 4-Dimer $\cdot$ Pyridine } \\
\hline $\mathrm{Zn}(1)-\mathrm{N}(1)$ & $1.996(3)$ & $\mathrm{Zn}(1) \cdots \mathrm{O}(1 \mathrm{~A})$ & $2.512(5)$ \\
\hline $\mathrm{Zn}(1)-\mathrm{N}(2)$ & $2.302(3)$ & $\mathrm{Zn}(1) \cdots \mathrm{Zn}(1 \mathrm{~A})$ & $4.025(3)$ \\
\hline $\mathrm{Zn}(1)-\mathrm{N}(3)$ & $1.994(3)$ & $\mathrm{Zn}(1)-\mathrm{O}(1)$ & $1.667(5)$ \\
\hline $\mathrm{Zn}(1)-\mathrm{N}(4)$ & $2.136(3)$ & $\begin{array}{l}\mathrm{Zn}(1)-\mathrm{O}\left(1^{\prime}\right) \\
\mathrm{Zn}(1) \cdots \mathrm{O}\left(1^{\prime} \mathrm{A}\right)\end{array}$ & $\begin{array}{l}1.774(4) \\
4.572(4)\end{array}$ \\
\hline $\mathrm{Zn}(1)-\mathrm{O}(1)-\mathrm{Zn}(1 \mathrm{~A})$ & 148.1(2) & $\mathrm{O}(1 \mathrm{~A})-\mathrm{Zn}(1)-\mathrm{N}(1)$ & $92.6(2)$ \\
\hline $\mathrm{O}(1)-\mathrm{Zn}(1)-\mathrm{N}(1)$ & $93.5(2)$ & $\mathrm{O}(1 \mathrm{~A})-\mathrm{Zn}(1)-\mathrm{N}(2)$ & $120.3(2)$ \\
\hline $\mathrm{O}(1)-\mathrm{Zn}(1)-\mathrm{N}(2)$ & $152.2(2)$ & $\mathrm{O}(1 \mathrm{~A})-\mathrm{Zn}(1)-\mathrm{N}(3)$ & $103.4(2)$ \\
\hline $\mathrm{O}(1)-\mathrm{Zn}(1)-\mathrm{N}(3)$ & $98.0(2)$ & $\mathrm{N}(1)-\mathrm{Zn}(1)-\mathrm{N}(3)$ & $163.43(12)$ \\
\hline $\mathrm{O}(1)-\mathrm{Zn}(1)-\mathrm{O}(1 \mathrm{~A})$ & $31.9(2)$ & $\mathrm{N}(2)-\mathrm{Zn}(1)-\mathrm{N}(3)$ & $87.77(11)$ \\
\hline $\mathrm{N}(1)-\mathrm{Zn}(1)-\mathrm{N}(2)$ & $87.61(11)$ & & \\
\hline
\end{tabular}

with a riding model. Compound $\mathbf{4}$-dimer $\bullet$ pyridine contains pyridine solvent molecules (with partial occupancy) located on inversion and orientationally disordered about it. Table 2 lists selected bond distances and angles for both complexes.

\section{Results and Discussion}

Molecular Structures of 3-Dimer and 4-Dimer. The X-ray structures are depicted in Figure 1a for complex 3-dimer and Figure $1 \mathrm{~b}$ for 4 -dimer. The molecular structures of crystalline 3-dimer may be described as a bimolecular unit in which each pair of centrosymmetrically related copper(II) ions, at a rather short distance of $\mathrm{Cu}(1) \cdots \mathrm{Cu}(1 \mathrm{~A})$ $=3.987(4) \AA$, share oxygen atoms, as shown by a dimeric 


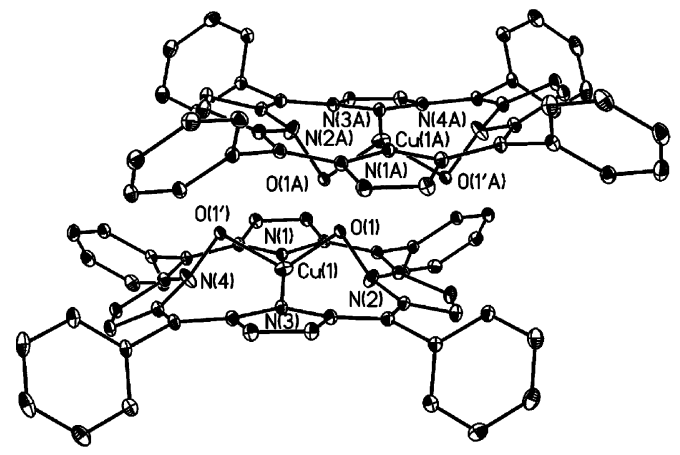

(a) 3-dimer

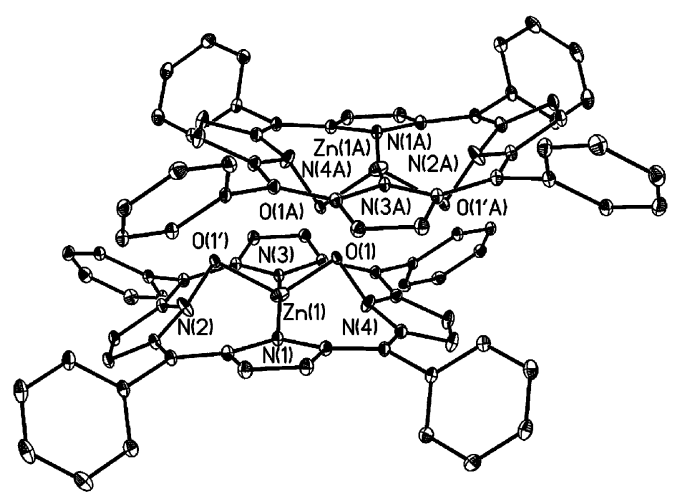

(b) 4-dimer

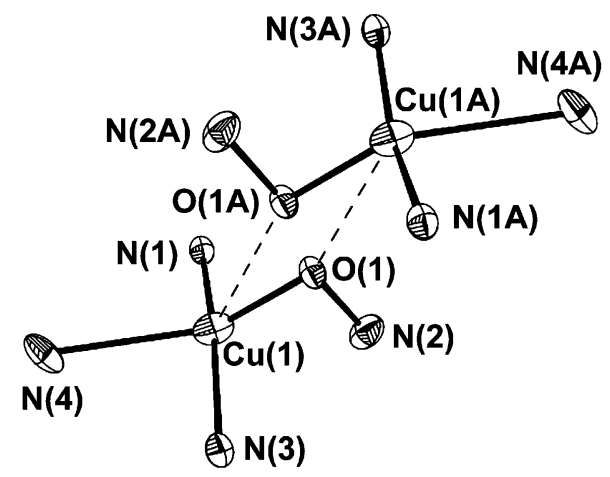

(c) dimeric unit of 3-dimer (37\%)

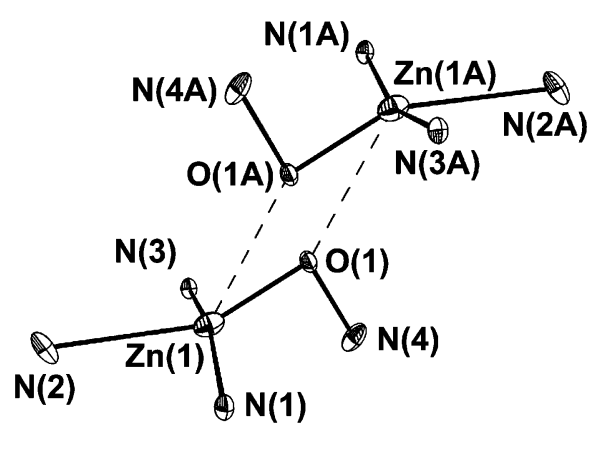

(d) dimeric unit of 4-dimer (40\%)

Figure 1. (a) Molecular configuration and atom-labeling scheme for $[\mathrm{Cu}(\operatorname{tpp}-\mathrm{N}-\mathrm{O})]_{2}$ (3-dimer) and (b) $\left[\mathrm{Zn}(\mathrm{tpp}-\mathrm{N} \text {-O) }]_{2}\right.$ (4-dimer), with ellipsoids drawn at $30 \%$ probability. (c) Schematic view of the dimeric copper(II) unit in 3-dimer (37\%). (d) Schematic view of the dimeric zinc(II) unit in 4-dimer (40\%). Hydrogen atoms, solvent $\mathrm{CHCl}_{3}$ for 3-dimer, and solvent pyridine for 4-dimer are omitted for clarity. The oxygen atom is disordered with an occupancy factor of 0.63 (or 0.60 ) for $\mathrm{O}\left(1^{\prime}\right)$ and 0.37 (or 0.40 ) for $\mathrm{O}(1)$ within 3-dimer (or 4-dimer), respectively.

unit of 3-dimer (37\%) in Figure 1c. Here, the geometry of the coordination of copper(II) is closely related to a distorted square-based pyramid, giving a trigonal distortion parameter $(\tau)$ value of $0.22,{ }^{27}$ with copper(II) having a coordination of five [4+1], $\mathrm{CuN}_{3} \mathrm{O}_{2}$, with normal bonds to $\mathrm{N}(1), \mathrm{N}(3), \mathrm{N}(4)$, and $\mathrm{O}(1)$ atoms and a longer bond to the $\mathrm{O}(1 \mathrm{~A})$ atom of the centrosymmetrically related molecule (Figure 1c). The $\mathrm{Cu}-$ (1) $\cdots \mathrm{O}(1 \mathrm{~A})$ bond $(2.488(7) \AA)$ is considerably longer than any of the other $\mathrm{Cu}(1)-\mathrm{N}(1.991(3), 1.995(4)$, and 2.332(4) $\AA)$ or $\mathrm{Cu}(1)-\mathrm{O}(1)(1.653(7) \AA)$ bonds. However, the $\mathrm{Cu}$ (1) $\cdots \mathrm{O}(1 \mathrm{~A})$ bond length is similar to that of $\mathrm{Cu}-\mathrm{O}=2.446$ (5) $\AA$ in $\mathrm{Cu}(\mathrm{Pc})\left(\mathrm{ReO}_{4}\right)_{2}{ }^{28}$ but is smaller than those of $\mathrm{Cu}(1)-$ $\mathrm{O}(2)=2.526(5) \AA$ in $\mathrm{Cu}(\mathrm{Pc})\left(\mathrm{ReO}_{4}\right)^{28}$ and of $\mathrm{Cu}(1)-\mathrm{O}(1)$ $=2.533(7) \AA$ in $\mathrm{Cu}_{3} \mathrm{~L}\left(\mathrm{CH}_{3} \mathrm{COO}\right)_{4} \cdot{ }^{29}$ This $\mathrm{Cu}(1) \cdots \mathrm{O}(1 \mathrm{~A})$ contact is also significantly shorter than the sum of the van der Waals radii of $\mathrm{Cu}$ and $\mathrm{O}(2.90 \AA)$ and may be described as a weak covalent bond. ${ }^{30}$ The bond distances $(\AA)$ are as follows: $\mathrm{Zn}(1) \cdots \mathrm{O}(1 \mathrm{~A})=2.512(5)$ and $\mathrm{Zn}(1)-\mathrm{O}(1)=$ 1.667(5), and the mean of $\mathrm{Zn}(1)-\mathrm{N}_{\mathrm{p}}=2.097$ (3) for 4-dimer

(27) Addison, A. W.; Rao, T. N.; Reedijk, J.; Rijn, J. V.; Verschoor, G. C. J. Chem. Soc., Dalton Trans. 1984, 1349.

(28) Gardberg, A. S.; Doan, P. E.; Hoffman, B. M.; Ibers, J. A. Angew. Chem., Int. Ed. 2001, 40, 244.

(29) Chiari, B.; Piovesana, O.; Tarantelli, T.; Zanazzi, P. F. Inorg. Chem. 1985, 24, 4615.

(30) Huheey, J. E.; Keiter, E. A.; Keiter, R. L.; Inorganic Chemistry, 4th ed.; Harper Collins College Publishers: New York, 1993; pp 114, 292.
(Figure 1b). The $\mathrm{Zn}(1) \cdots \mathrm{O}(1 \mathrm{~A})$ distance is longer than the sum of the covalent radii of $\mathrm{Zn}$ and $\mathrm{O}(1.93 \AA)$ but is significantly shorter than sum of the van der Waals radii of $\mathrm{Zn}$ and $\mathrm{O}(2.90 \AA) .{ }^{30}$ This longer $\mathrm{Zn}(1) \cdots \mathrm{O}(1 \mathrm{~A})$ contact is too long to be considered as a true coordinated bond and may be viewed as a secondary intermolecular interaction. This kind of secondary interaction was previously observed for $\mathrm{Zn}(\mathrm{tpp})(\mathrm{THF})_{2}$ with $\mathrm{Zn}-\mathrm{O}=2.536(7) \AA^{31}$ and for $\mathrm{Zn}$ $\left[\mathrm{T}\left(2^{\prime}, 6^{\prime}\right.\right.$-DHP)P $(\text { EtOAc })_{2} \cdot 2 \mathrm{EtOAc}$ with $\mathrm{Zn}-\mathrm{O}=2.532(3)$ $\AA .{ }^{32}$ The effective coordination for 4-dimer is then denoted as $[4+1], \mathrm{ZnN}_{3} \mathrm{O}_{2}$. The $\mathrm{Zn}(1)$ atom in 4-dimer has a distorted square-pyramidal $[4+1]$ coordination geometry that gives a $\tau$-value of 0.19 . The $\mathrm{Zn}(1) \cdots \mathrm{Zn}(1 \mathrm{~A})$ distance is 4.025(3) $̊$ in the dimeric unit of 4-dimer (40\%) (Figure 1d). The structure suffers from disorder in the location of the oxygen atom. There is only one oxygen atom per 3 -monomer or 4-monomer. However, the macrocycle of $\mathbf{3}$-monomer is packed so that the oxygen atom occupies two sites which are shown in Figure 2a with $63 \%$ occupancy at $\mathrm{O}\left(1^{\prime}\right)$ and $37 \%$ occupancy at $\mathrm{O}(1){ }^{2}$ The whole molecule of $\mathbf{3}$-monomer resulting from these arrangements is shown in parts $\mathrm{b}$ and $\mathrm{c}$ of Figure 2. A similar kind of disorder with $60 \%$ occupancy

(31) DiMagno, S. G.; Lin, V. S. Y.; Therien, M. J. J. Am. Chem. Soc. 1993, 115, 2513.

(32) Bhyrappa, P.; Wilson, S. R.; Suslick, K. S. J. Am. Chem. Soc. 1997, 119,8492 . 
Yang et al.

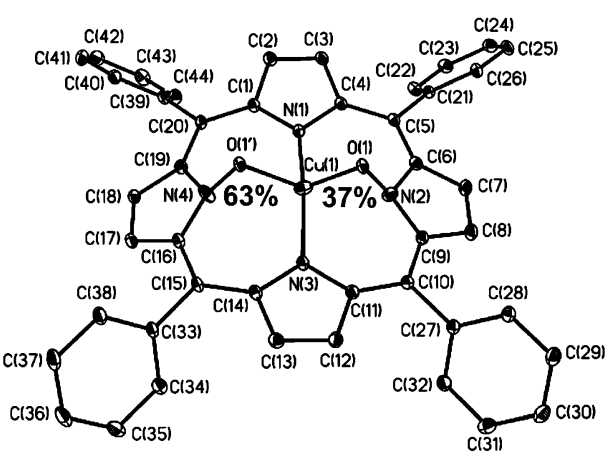

(a) 3-monomer

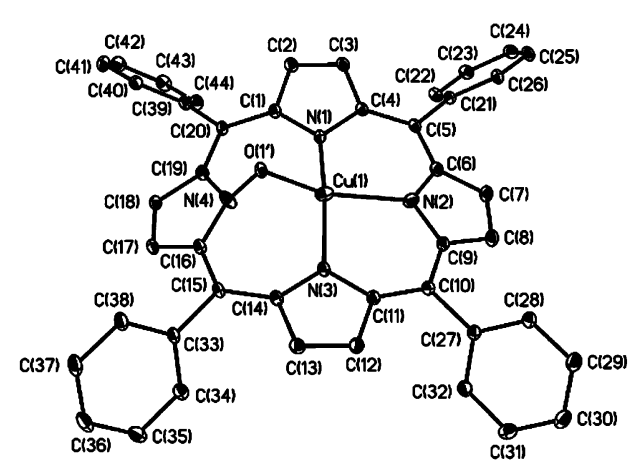

(b) 3-monomer (63\%)

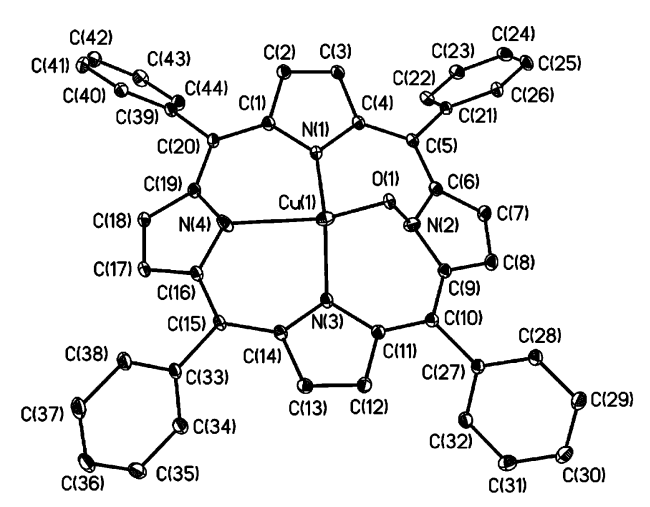

(c) 3-monomer (37\%)

Figure 2. (a) Drawing of the asymmetric unit (3-monomer) in 3-dimer, showing the atom numbering scheme. Due to the disorder, the $\mathrm{O}\left(1^{\prime}\right)$ and $\mathrm{O}(1)$ sites each have 0.63 and 0.37 occupancies, respectively. (b) View of 3-monomer with the site of $\mathrm{O}\left(1^{\prime}\right)$, which has an occupancy of 0.63 . (c) View of 3-monomer with the site of $\mathrm{O}(1)$, which has an occupancy of 0.37 .

at $\mathrm{O}\left(1^{\prime}\right)$ and $40 \%$ occupancy at $\mathrm{O}(1)$ for 4 -monomer is shown at Figure S1 (in the Supporting Information). The $\mathrm{M}-\mathrm{O}$ values for the major species are shown in Table 2 and in Figure S3 (in the Supporting Information). The geometry around $\mathrm{Cu}(1)$ is a distorted square planar in 3-dimer (63\%) and that around $\mathrm{Zn}(1)$ is also a distorted square planar in 4-dimer (60\%) (parts b and $f$ of Figure $S 3$ in the Supporting Information). Bond distances $(\AA)$ are $\mathrm{Cu}(1)-\mathrm{N}(1)=1.991$ (3), $\mathrm{Cu}(1)-\mathrm{N}(2)=2.130(4), \mathrm{Cu}(1)-\mathrm{N}(3)=1.995(4)$, and $\mathrm{Cu}(1)-\mathrm{O}\left(1^{\prime}\right)=1.775(4)$ for 3-dimer $(63 \%)$; for 4-dimer $(60 \%)$, the values are $\mathrm{Zn}(1)-\mathrm{N}(3)=1.994(3), \mathrm{Zn}(1)-\mathrm{N}(4)$ $=2.136(3), \mathrm{Zn}(1)-\mathrm{N}(1)=1.996(3)$, and $\mathrm{Zn}(1)-\mathrm{O}\left(1^{\prime}\right)=$
1.774(4). Since the dimeric unit in the minor occupancy oxygen atom gives a clearly weak axial interaction in the solid state (parts c and d of Figure 1 and parts $\mathrm{d}$ and $\mathrm{h}$ of Figure S3 in the Supporting Information), all the $\mathrm{M}-\mathrm{O}$ distances lead to the usage of the minor occupancy oxygen atom.

Spin-Pair Hamiltonian. The Hamiltonian for the exchange coupling between the two copper(II) paramagnetic centers 1 and 2 in 3-dimer with local electronic spin $S_{1}=S_{2}$ $=1 / 2$ can be written as ${ }^{33-39}$

$$
\begin{array}{r}
\hat{\mathrm{H}}=-2 J S_{1} \cdot S_{2}+S_{1} \cdot D_{12} \cdot S_{2}+\sum_{i=1}^{2}\left(S_{i} \cdot D_{i} \cdot S_{i}+\beta H g_{i} \cdot S_{i}+\right. \\
\left.S_{i} \cdot A_{i} \cdot I_{i}\right)^{34}
\end{array}
$$

where the terms correspond to isotropic exchange coupling, dipolar exchange coupling, single-ion zero-field splitting, electronic Zeeman splitting, and hyperfine interaction $\left(I_{\mathrm{Cu}}\right.$ $=3 / 2$ ) on each copper(II) center, respectively. Here $H$ is the static magnetic field; $\beta$ is the Bohr magneton; $J$ is the isotropic exchange interaction constant; $A_{1}, A_{2}, I_{1}$, and $I_{2}$ are hyperfine interaction tensors and nuclear spin of ions one and two; $g_{1}, g_{2}, D_{1}$, and $D_{2}$ are the $g$ tensors and the singleion zero-field splitting tensor of ions one and two, respectively; and $D_{12}$ is the zero-field splitting arising from the coupling of the spins. The latter term is due to anisotropic exchange interactions $\left(D^{\mathrm{ex}}\right)$ and magnetic dipole-dipole interactions $\left(D^{\mathrm{dip}}\right)$ :

$$
D_{12}=D^{\text {ex }}+D^{\text {dip }}
$$

If the term in $J$ is much greater than other terms, the total electronic spin $S$ is a good quantum number and is given by $S=1,0$. The Hamiltonian written as eq 1 thus reduces to

$$
\begin{array}{r}
H_{\mathrm{s}}=-J\left[S(S+1)-S_{1}\left(S_{1}+1\right)-S_{2}\left(S_{2}+1\right)\right]+\beta H g_{\mathrm{s}} \cdot \vec{S}+ \\
D_{\mathrm{s}}\left[S_{z}^{2}-\frac{1}{3} S(S+1)\right]+E_{\mathrm{s}}\left(S_{\mathrm{x}}^{2}-S_{\mathrm{y}}^{2}\right)+S \cdot\left(A_{1, \mathrm{~s}} \cdot I_{1}+A_{2, \mathrm{~s}} \cdot I_{2}\right)
\end{array}
$$

Here, $D_{\mathrm{s}}$ and $E_{\mathrm{s}}$ are the axial and rhombic zero-field splitting for the exchange-coupled dimer in the spin state $S$, respectively; $\vec{S}$ is the total spin operator; and $A_{1, \mathrm{~s}}$ and $A_{2, \mathrm{~s}}$ are the hyperfine coupling constants for the $S$-spin state of nuclei 1 and 2, respectively, in the coupled system.

For spectra of pairs in the strong exchange limit, one can establish the following relations:

$$
g_{\mathrm{s}}=\frac{g_{1}+g_{2}}{2}
$$

(33) Owen, J. J. Appl. Phys. 1961, 32, 213S.

(34) Chao, C. C. J. Magn. Reson. 1973, 10, 1.

(35) Scaringe, R. P.; Hodgson, D. J.; Hatfield, W. E. Mol. Phys. 1978, 35, 701.

(36) Bencini, A.; Gatteschi, D. Mol. Phys. 1985, 54, 969.

(37) Zheng, M.; Khangulov, S. V.; Dismukes, G. C.; Barynin, V. V. Inorg. Chem. 1994, 33, 382.

(38) Bencini, A.; Gatteschi, D. EPR of Exchange Coupled Systems; Springer-Verlag: Berlin, 1990; pp 48-55.

(39) Howard, T.; Telser, J.; DeRose, V. J. Inorg. Chem. 2000, 39, 3379. 


$$
A_{1, \mathrm{~s}}=\frac{1}{2} A_{1} ; \quad A_{2, \mathrm{~s}}=\frac{1}{2} A_{2}
$$

The tensor $D_{\mathrm{s}}$ is related to the component tensors $D_{1}$ and $D_{2}$ by the relation $D_{\mathrm{s}}=d_{1} D_{1}+d_{2} D_{2}+d_{12} D_{12}{ }^{38}$ For the $S_{1}=$ $1 / 2, S_{2}=1 / 2$ system, these coefficients for the spin-coupled system are as follows: $S=1, d_{1}=d_{2}=0$, and $d_{12}=1 / 2$.

$$
D_{\mathrm{s}}=\frac{1}{2} D_{12}=\frac{1}{2} D^{\mathrm{dip}}+\frac{1}{2} D^{\mathrm{ex}}=D_{\mathrm{s}}^{\mathrm{dip}}+D_{\mathrm{s}}^{\mathrm{ex}}
$$

$D_{\mathrm{s}}$ is composed of two terms, $D_{\mathrm{s}}^{\text {dip }}=1 / 2 D^{\text {dip }}$ (from the electron-electron dipolar interaction) and $D_{\mathrm{s}}^{\mathrm{ex}}=1 /{ }_{2} D^{\mathrm{ex}}$ (from spin-orbit coupling) for the coupled system. ${ }^{40} D_{\mathrm{s}}^{\mathrm{dip}}$ is related to the $\mathrm{Cu}-\mathrm{Cu}$ separation $r$ by eq $7^{41,42}$

$$
D_{\mathrm{s}}^{\mathrm{dip}}=\frac{-\left(2 g_{\|}^{2}+g_{\perp}^{2}\right) \beta^{2}}{2 r^{3}}
$$

ESR Studies. X-band ESR spectra have been obtained for 3-dimer in powder form at 293 and $4 \mathrm{~K}$ (Figure 3) and 3-monomer in $\mathrm{CHCl}_{3}\left(\right.$ or $\mathrm{CH}_{2} \mathrm{Cl}_{2}$ ) at $293 \mathrm{~K}$ (Figure 4). Figure 3 shows a pair of signals on both sides of the monomer copper species signal with a separation of $780 \mathrm{G}$ and a singlet at about $1617 \mathrm{G}$. These two signals are characteristic of triplet dimeric copper species; that is, the paired signals at high field are ascribed to the $\Delta M_{\mathrm{s}}=1$ transitions and the signal at low field to the $\Delta M_{\mathrm{s}}=2$ transition. The observation of only a pair of signals at high field suggests that the triplet dimeric species has near or complete axial symmetry with $E_{\mathrm{s}} \approx 0$, the value of $780 \mathrm{G}$ corresponding to a zero-field splitting parameter, $D_{\mathrm{s} .}{ }^{43-46}$ The $D_{\mathrm{s}}$ value derived from the position of the $\Delta M_{\mathrm{s}}=2$ transition is $0.0743 \mathrm{~cm}^{-1},{ }^{47-49}$ whereas the value obtained from the $\Delta M_{\mathrm{s}}=1$ transition is $0.0731 \mathrm{~cm}^{-1}{ }^{44}$ The very good agreement between the two values confirms that the preceding assignment of observed spectrum to a triplet species and the analysis of the fine structure are correct. Lowering the sample temperature to 4 $\mathrm{K}$ at perpendicular mode allowed the detection, at high gain, of seven clearly resolved copper hyperfine lines of an average separation of $79.6 \mathrm{G}$ with relative intensities of $1: 2: 3: 4: 3$ : $2: 1$, on the low-field side of the $\Delta M_{\mathrm{s}}=2$ signal (Figure 3b). This seven-line structures can be attributed to the hyperfine structure from two copper nuclei with $I=3 / 2$ and is characteristic of a dimeric $\mathrm{Cu}$ (II) triplet state. The similar

(40) Collman, J. P.; Elliott, C. M.; Halbert, T. R.; Tovrog, B. S. Proc. Natl. Acad. Sci. U.S.A. 1977, 74, 18.

(41) Ross, P. K.; Allendorf, M. D.; Solomon, E. I. J. Am. Chem. Soc. 1989 $111,4009$.

(42) Muto, Y.; Nakashima, M.; Tokii, T.; Suzuki, I.; Ohba, S.; Steward, O. W.; Kato, M. Bull. Chem. Soc. Jpn. 2002, 75, 511.

(43) Wasserman, E.; Snyder, L. C.; Yager, W. A. J. Chem. Phys. 1964, 41,1763

(44) Weil, J. A.; Bolton, J. R.; Wertz, J. E. Electron Paramagnetic Resonance Elementary Theory and Practical Applications; John Wiley and Sons, Inc.: New York, 1994; pp 162-170.

(45) Konishi, S.; Hoshino, M.; Imamura, M. J. Am. Chem. Soc. 1982, 104, 2057.

(46) Satoh, M.; Ohba, Y.; Hoshino, M.; Konishi, S.; Ebina, F.; Yamauchi, S.; Iwaizumi, M. Bull. Chem. Soc. Jpn. 1999, 72, 2389.

(47) Eaton, S. S.; More, K. M.; Sawant, B. M.; Eaton, G. R. J. Am. Chem. Soc. 1983, 105, 6560 .

(48) Walls, J. H. V. D.; Groot, M. S. Mol. Phys. 1959, 2, 333.

(49) Groot, M. S.; Walls, J. H. V. D. Mol. Phys. 1960, 3, 190.
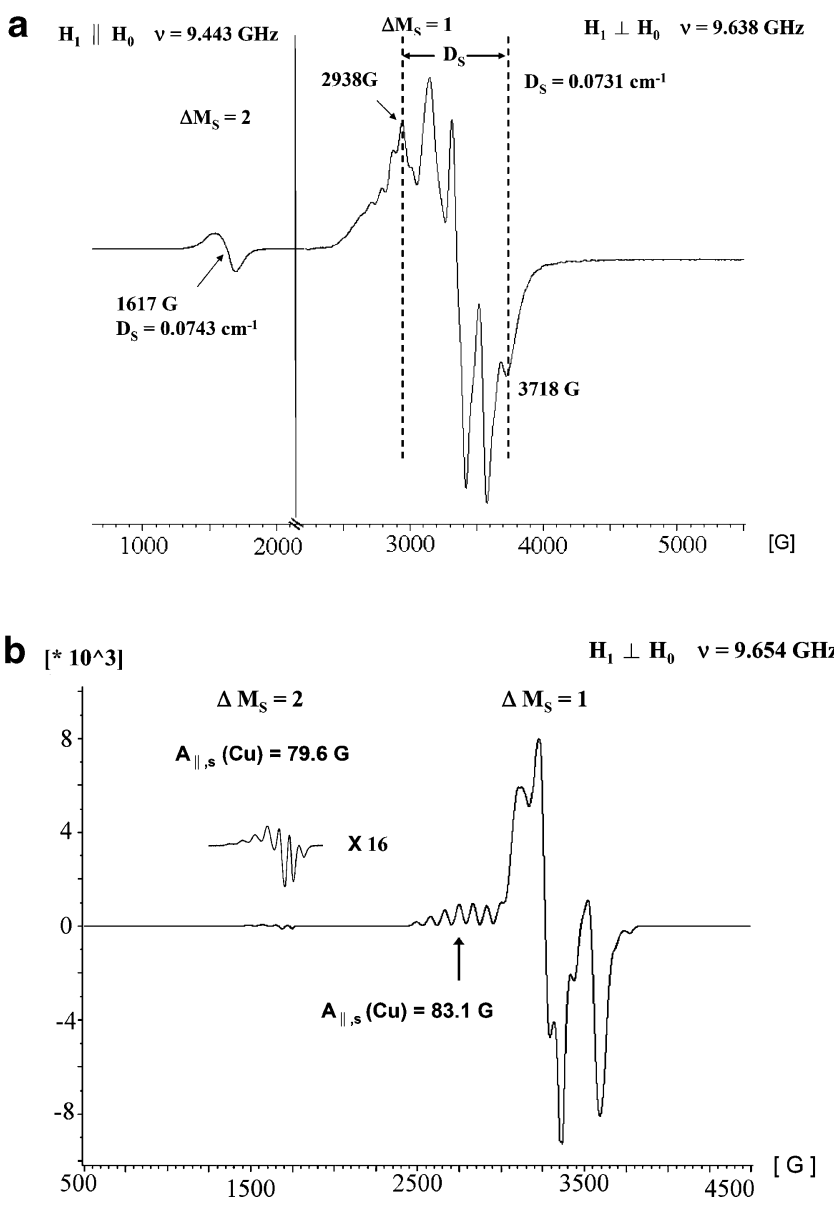

Figure 3. (a) X-band ESR powder spectra for 3-dimer at $293 \mathrm{~K}$. Lowfield region of the spectra: $\Delta M_{\mathrm{s}}=2, H_{1} \| H_{0}$, frequency $v=9.443 \mathrm{GHz}$ High-field region of the spectra: $\Delta M_{\mathrm{s}}=1, H_{1} \perp H_{0}$, frequency $v=9.638$ GHz. ESR conditions: microwave power of $20.09 \mathrm{~mW}\left(\Delta M_{\mathrm{s}}=2\right)$ and $19.97 \mathrm{~mW}\left(\Delta M_{\mathrm{s}}=1\right)$, magnetic field modulation amplitude of $2 \mathrm{G}\left(\Delta M_{\mathrm{s}}\right.$ $=2)$ and $1.6 \mathrm{G}\left(\Delta M_{\mathrm{s}}=1\right)$, modulation frequency of $100.00 \mathrm{kHz}$. (b) X-band ESR powder spectra for 3-dimer at $4 \mathrm{~K}$. ESR conditions for perpendicular mode of spectrum: microwave frequency of $9.654 \mathrm{GHz}$, microwave power of $2.002 \mathrm{~mW}$, magnetic field modulation amplitude of $1.6 \mathrm{G}$, and modulation frequency of $100.00 \mathrm{kHz}$.

kinds of seven-line hyperfine structure were observed with a separation of $74 \mathrm{G}$ (or $81.8 \mathrm{G}$ ) in the $\Delta M_{\mathrm{s}}=2$ transition for dicopper(II) complexes of a 28-membered $\mathrm{N}_{8}$ macrocycle $\left[\mathrm{Cu}(\mathrm{HL})(\mathrm{MeCN})_{2}\right]\left(\mathrm{BPh}_{4}\right)_{3}{ }^{50}$ (or $\left.\mathrm{Na}_{2} \mathrm{Cu}-d l-\mathrm{C}_{4} \mathrm{O}_{6} \mathrm{H}_{2} \cdot 5 \mathrm{H}_{2} \mathrm{O}\right){ }^{51}$ The first six lines with relative intensities of 1:2:3:4:3:2 of a seven-line $g_{\|}$pattern $\left(g_{\|}=2.51\right)$ are also discernible on the low-field "wing" of the $\Delta M_{\mathrm{s}}=1$ signal (Figure $3 \mathrm{~b}$ ), and the remainder of the signal is overlapped by the more intense $g_{\perp}$ component $\left(g_{\perp}=2.11\right)$. The splitting constant $\left(A_{\|, \mathrm{s}}(\mathrm{Cu})\right.$ $=83.1 \mathrm{G})$ in the $\Delta M_{\mathrm{s}}=1$ transition is close to that with $A_{\|}$ $(\mathrm{Cu})=77-82 \mathrm{G}$ observed for $\left[\mathrm{Cu}(\mathrm{HL})(\mathrm{MeCN})_{2}\right]\left(\mathrm{BPh}_{4}\right)_{3}{ }^{50}$ and with $78.3 \mathrm{G}$ observed for $\mathrm{Na}_{2} \mathrm{Cu}-d l-\mathrm{C}_{4} \mathrm{O}_{6} \mathrm{H}_{2} \cdot 5 \mathrm{H}_{2} \mathrm{O} .{ }^{51}$ The hyperfine coupling constant $\left(A_{\|, \mathrm{s}}(\mathrm{Cu})=83.1 \mathrm{G}\right)$ obtained from $\Delta M_{\mathrm{s}}=1$ is just slightly more than that with $\left(A_{\|, \mathrm{s}}(\mathrm{Cu})\right.$ $=79.6 \mathrm{G}$ ) observed for the $\Delta M_{\mathrm{s}}=2$ signal, and this average data of $81 \pm 2 \mathrm{G}$ provides a good estimation of the interaction between two copper centers in $\mathbf{3}$-dimer.

(50) Drew, M. G. B.; Marphy, B. P.; Nelson, J.; Nelson, S. M. J. Chem. Soc., Dalton Trans. 1987, 873

(51) Chasteen, N.; Belford, R. L. Inorg. Chem. 1970, 9, 169. 
Yang et al.
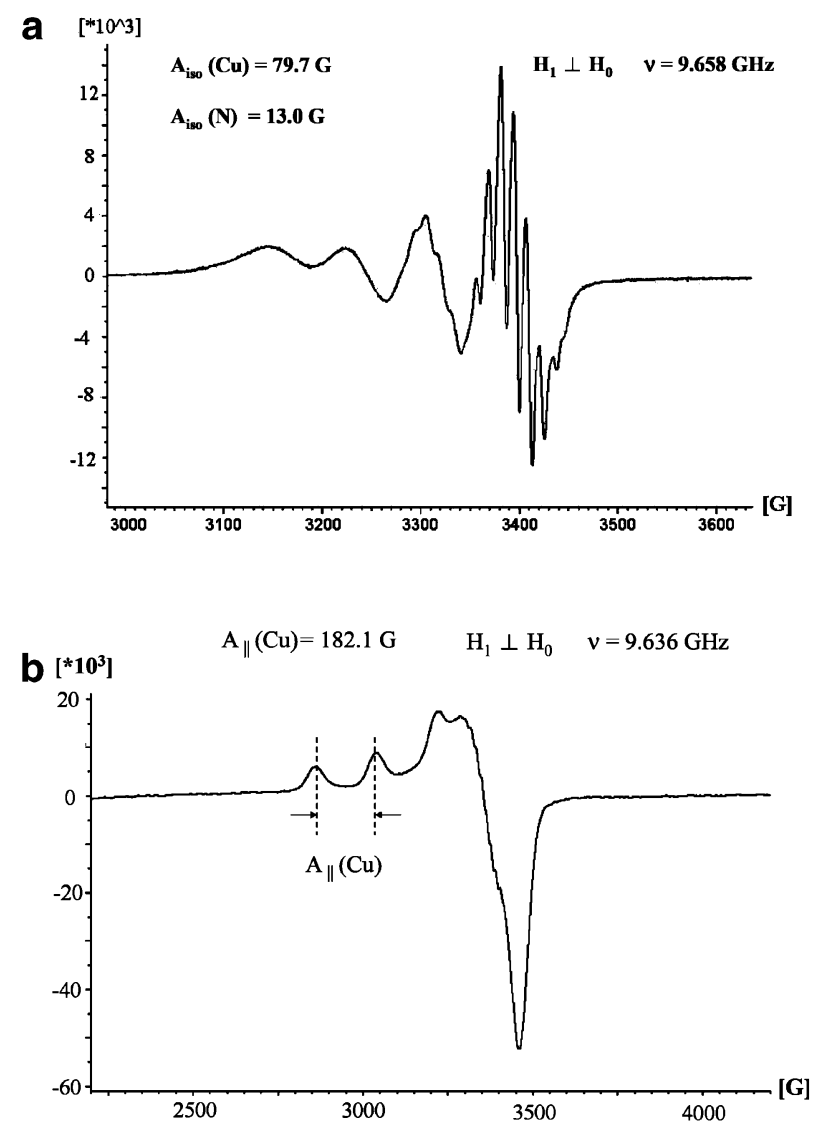

Figure 4. (a) $\mathrm{X}$-band $\mathrm{ESR}$ spectra for $\mathrm{Cu}\left(\mathrm{tpp}-\mathrm{N}\right.$-O) (3-monomer) in $\mathrm{CHCl}_{3}$ (or $\mathrm{CH}_{2} \mathrm{Cl}_{2}$ ) at $293 \mathrm{~K}$. ESR conditions: microwave frequency of $9.658 \mathrm{GHz}$, microwave power of $20.11 \mathrm{~mW}$, modulation amplitude of $2.0 \mathrm{G}$, and modulation frequency of $100.00 \mathrm{kHz}$. (b) X-band ESR spectra for $\mathrm{Cu}(\mathrm{tpp}-$ $N$-O) (3-monomer) in $\mathrm{CHCl}_{3}$ (or $\mathrm{CH}_{2} \mathrm{Cl}_{2}$ ) at $77 \mathrm{~K}$. ESR conditions: microwave frequency of $9.636 \mathrm{GHz}$, microwave power of $20.07 \mathrm{~mW}$, modulation amplitude of $1.6 \mathrm{G}$, and modulation frequency of $100.00 \mathrm{kHz}$.

The ESR spectra of 3-dimer in $\mathrm{CH}_{2} \mathrm{Cl}_{2}$ at $20{ }^{\circ} \mathrm{C}$ shown in Figure 4 indicate that dissociation occurs (since only monomeric structure $\mathrm{Cu}(\operatorname{tpp}-N-\mathrm{O})$ with normal $S=1 / 2$ spectra were obtained). The spectra are typical for planar copper(II) complex with $g_{\text {iso }}=2.060, A_{\text {iso }}\left({ }^{63} \mathrm{Cu}\right)=79.7 \mathrm{G}$, and $A_{\text {iso }}\left({ }^{14} \mathrm{~N}\right)=13.0 \mathrm{G}$ for 3-monomer in $\mathrm{CHCl}_{3}\left(\right.$ or $\left.\mathrm{CH}_{2} \mathrm{Cl}_{2}\right)$ at $20{ }^{\circ} \mathrm{C}$ (shown in Figure 4a) and with $g_{\|}=2.19$ and $A_{\|}\left({ }^{63} \mathrm{Cu}\right.$ ) $=182.1 \mathrm{G}$ for 3-monomer in $\mathrm{CHCl}_{3}\left(\right.$ or $\left.\mathrm{CH}_{2} \mathrm{Cl}_{2}\right)$ at $77 \mathrm{~K}$ (shown in Figure 4b). These hyperfine couplings are similar in magnitudes to those of $g_{\text {iso }}=2.082, A_{\text {iso }}\left({ }^{63} \mathrm{Cu}\right)=77 \mathrm{G}$, and $A_{\text {iso }}\left({ }^{14} \mathrm{~N}\right)=13.7 \mathrm{G}$ and of $g_{\|}=2.196$ and $A_{\|}\left({ }^{63} \mathrm{Cu}\right)=$ $166 \mathrm{G}$ obtained either from copper(II) octaethylporphyrin $\mathrm{N}$-oxide [Cu(OEP-N-O)] 2 in toluene solution at $23{ }^{\circ} \mathrm{C}$ or from $1 \%$ of sample 2 doped in octaethylporphyrin $\mathrm{N}$-oxide at the same temperature. ${ }^{2}$ The pattern of nitrogen hyperfine coupling in the porphyrins $N$-oxide complex is significant, since in solution only seven lines with relative intensities of 1:3:6:7:6:3:1 are seen due to hyperfine interaction with nitrogen. Consequently, it appears that the unpaired spin in $\mathrm{Cu}$ (II) is interacting with three nearly equivalent nuclei rather than with four nitrogens, which is the usual case for porphyrins where a nine-line pattern is observed. We take this to be a further indication that this complex has a structure analogous to 3 -monomer shown in parts $\mathrm{b}$ and $\mathrm{c}$ of Figure 2. We cannot detect the resonances of $\Delta M_{\mathrm{s}}= \pm 2$ at the

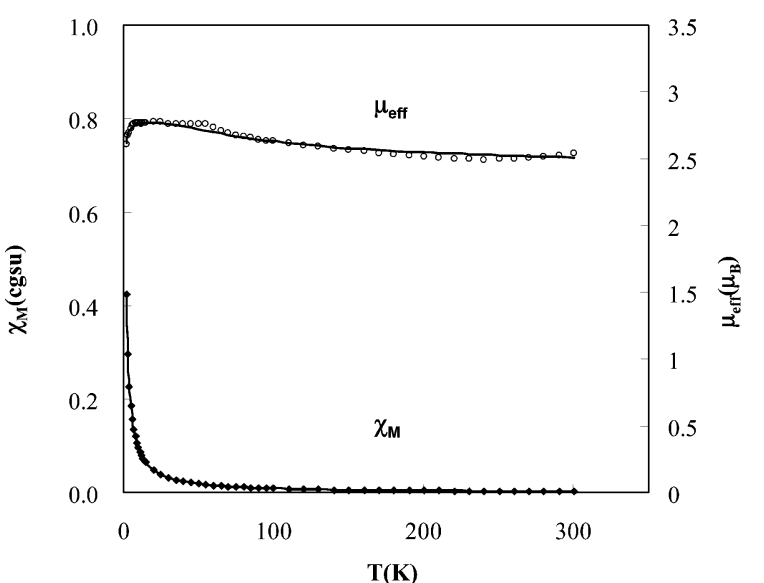

Figure 5. Temperature variation of the molar magnetic susceptibility $\left(\chi_{\mathrm{m}}\right)$ and effective magnetic moment ( $\left.\mu_{\text {eff }}\right)$ for the powder sample of $\mathbf{3}$-dimer in the range of $5-300 \mathrm{~K}$. Points are the experimental data; solid lines represent the least-squares fit of the data to eq 8 .

half-field in the parallel mode for 3-dimer in $\mathrm{CHCl}_{3}$ at 77 $\mathrm{K}$; hence, there is no hint of forming a dimeric species in frozen solution at $77 \mathrm{~K}$. This dimerization is the solid-state lattice effect of solid-state packing with an extremely small association constant. ${ }^{52}$

Anisotropic Exchange Contribution to Zero-Field Splitting. Anisotropic exchange or pseudo-dipolar coupling $\left(D_{\mathrm{s}}^{\mathrm{ex}}\right)$ has been widely used to explain the ground-state triplet zero-field splitting in copper dimer. Applying eq 7 and $r=3.987 \AA$ for the $\mathrm{Cu}-\mathrm{Cu}$ distance from X-ray data of 3-dimer yields $D_{\mathrm{s}}^{\mathrm{dip}}=-0.058 \mathrm{~cm}^{-1}$ and this gives the opposite sign of the experimental ground-state zero-field splitting of $D_{\mathrm{s}}=0.074 \mathrm{~cm}^{-1}$. The values of $D_{\mathrm{s}}^{\mathrm{ex}}(=0.132$ $\mathrm{cm}^{-1}$ ) were obtained by substituting the values of $D_{\mathrm{s}}$ and $D_{\mathrm{s}}^{\text {dip }}$ into eq 6 . These results show that in 3-dimer the anisotropic exchange interaction $D_{\mathrm{s}}^{\mathrm{ex}}$ gives the main contribution to $D_{\mathrm{s}}$. Per the hypothesis that all of the $D_{\mathrm{s}}$ interactions arise due to dipolar interaction $D_{\mathrm{s}}^{\mathrm{dip}}$, the measured $D_{\mathrm{s}}$ values can be used to estimate the metal-metal $\left(\mathrm{Cu}^{2+} \cdot \mathrm{Cu}^{2+}\right)$ separation, $r$, by eq $7 .^{51}$ Meanwhile, Bencini et al. ${ }^{38}$ have emphasized that in the hypothesis of the dipolar interaction, the intensity of the $\Delta M_{\mathrm{s}}= \pm 2$ transition in single crystals depends on $r^{-6}$. Moreover, the anisotropic exchange interaction $D_{\mathrm{s}}^{\mathrm{ex}}$ gives the significant contribution to $D_{\mathrm{s}}$ in 3-dimer. Hence, the approximate value of the $\mathrm{Cu}^{2+} \cdot \mathrm{Cu}^{2+}$ distance from the half-field spectrum in 3-dimer is not calculated.

Magnetic Properties. Magnetic data for complex 3-dimer are reported in Figure 5 in the forms of $\chi_{\mathrm{m}}$ and $\mu_{\text {eff }}$ versus $T$. As can be seen in Figure 5, the effective magnetic moment $\mu_{\text {eff }}$ for 3-dimer gradually increases from $2.54 \mu_{\mathrm{B}}$ at $300 \mathrm{~K}$ to $2.77 \mu_{\mathrm{B}}$ at $10 \mathrm{~K}$. This increase of $\mu_{\mathrm{eff}}$ as the temperature decreases indicates that $S=1$ is the ground state. Below 10 $\mathrm{K}$, the $\mu_{\text {eff }}$ drops slowly to $2.60 \mu_{\mathrm{B}}$ at $2 \mathrm{~K}$, reflecting the unavoidable zero-field splitting $D_{\mathrm{s}}$ of the ground state in 3-dimer. The data were fitted by the Bleaney-Bowers ${ }^{22,53}$

(52) Scheidt, W. R.; Mondal, J. U.; Eigenbrot, C. W.; Adler, A.; Radonovich, L. J.; Hoard, J. L. Inorg. Chem. 1986, 25, 795.

(53) The influence of $J$ interactions and zero-field effects on the energy levels of 3-dimer is shown in Figure S2 in the Supporting Information. 
equation (8) and a term $p$ which is fraction of any paramagnetic impurity, i.e., $\mathrm{Cu}^{2+}$.

$\chi_{\mathrm{m}}=\frac{\underline{\mathrm{Ng}} \mathrm{g}^{2} \beta^{2}}{\mathrm{kT}} \frac{2}{\mathrm{Cu}^{2+}-\mathrm{Cu}^{2+}(\text { dimer })} \overbrace{\frac{2}{2+\mathrm{e}^{\mathrm{D}_{\mathrm{s}} / \mathrm{kT}}+\mathrm{e}^{\left(-2 \mathrm{~J}+\mathrm{D}_{\mathrm{s}} / 3\right) / \mathrm{kT}}}}^{\mathrm{Cu}^{2+}}(1-\mathrm{p})+\underline{\mathrm{N} p \frac{\mathrm{g}^{2} \beta^{2}}{4 \mathrm{kT}}}+\mathrm{TIP}$

Here, $g$ is the average $g$ value, TIP is the temperatureindependent paramagnetism, $\underline{N}$ is Avogadro's number, $p$ is the fraction of the paramagnetic impurity, and other symbols have their usual meanings. The best fits as represented in Figure 5 gave the values of $g=2.01,2 J=68 \mathrm{~cm}^{-1}, p=$ 0.06 , and the temperature-independent paramagnetism value TIP $=1 \times 10^{-6} \mathrm{~cm}^{3} / \mathrm{mol}$ by substitution of the value of $D_{\mathrm{s}}$ $=0.074 \mathrm{~cm}^{-1}$ into eq 8 . The negative value of $-2 J$ indicates the ferromagnetic nature of spin coupling. This places the $S$ $=0$ state at about $68 \mathrm{~cm}^{-1}$ above the $S=1$ ground state.

From eq 5 , it is apparent that the hyperfine splitting $A_{\|, \mathrm{s}}$ is half that for a related mononuclear copper $\left(S_{1}=1 / 2\right)$ system $\left(A_{\|}\right)$. This relation has been found to hold to a reasonably good approximation in several instances. ${ }^{39,40,54,55}$ The species 3-monomer originating from the dissociation of 3-dimer is a mononuclear $\mathrm{Cu}^{2+}$ ion, and its hyperfine constant is a qualified constant for $A_{\|}$. Although we found that $A_{\|, \mathrm{s}}$ in 3-dimer is $81 \pm 2 \mathrm{G}$ (Figure $3 \mathrm{~b}$ ), smaller than what would be expected from eq 5 , since $A_{\|}$for the 3-monomer is 182.1 $\mathrm{G}$ (Figure 4b). Moreover, the resulting copper hyperfine splitting in 3-dimer expressed in wavenumbers with $A_{\|, \mathrm{s}}=$

(54) Blanchard, S.; Blondin, G.; Riviere, E.; Nierlich, M.; Girerd, J. J. Inorg. Chem. 2003, 42, 4568 .

(55) Buluggiu, E. J. Phys. Chem. Solids 1980, 41, 1175.
$(9.6 \pm 0.2) \times 10^{-3} \mathrm{~cm}^{-1}$ is close to half of the corresponding hyperfine splitting in 3-monomer with $1 /{ }_{2} A_{\|}=9.35 \times 10^{-3}$ $\mathrm{cm}^{-1}$. This supports that the magnetic exchange of copper pairs in 3-dimer is in the strong coupling limit.

\section{Conclusions}

We have investigated two new metal complexes, namely, one paramagnetic, binuclear copper(II) and one diamagnetic, binuclear zinc(II) porphyrin $N$-oxide; complexes of 3-dimer and 4-dimer and their X-ray structures are established. We have also reported for the first time the ESR spectra of $[\mathrm{Cu}-$ (tpp-N-O) $]_{2}$ (3-dimer) in powder form at 293 and $4 \mathrm{~K}$. Structural and ESR studies showed that 3-dimer produces a spin triplet ground state formed by ferromagnetic coupling between the two $\mathrm{d}^{9} \mathrm{Cu}^{\mathrm{II}}$ ions. The results clearly show that when pure single crystals of $\mathbf{3}$-dimer are dissolved in $\mathrm{CHCl}_{3}$ (or $\mathrm{CH}_{2} \mathrm{Cl}_{2}$ ) solvent, the principal copper species is 3-monomer.

Acknowledgment. The financial support from the National Science Council of the R.O.C. under Grant NSC 952113-M-005-014-MY3 and NSC 95-2113-M-273-002 is gratefully acknowledged.

Supporting Information Available: Figure S1 showing the atom numbering scheme for 4-monomer; Figure S2 showing the influence of $J$ interactions and zero-field effects on the energy levels of 3-dimer; X-ray crystallographic files in CIF formal for compounds 3-dimer and 4-dimer are also depicted. This material is available free of charge via the Internet at http://pubs.acs.org.

IC0611802 